\title{
Heat Stress Standard for Hot Work Environments in Japan
}

\author{
Masatoshi TANAKA
}

\author{
Fukushima College, 1-1 Chigoike, Miyashiro, Fukushima City, Fukushima 960-0181, Japan
}

Received February 20, 2006 and accepted October 20, 2006

\begin{abstract}
Threshold limit values (TLVs) are intended to protect workers from the severest effects of thermal stress and to establish the exposures to heat in working conditions. Earlier, acute heat strokes often occurred as a result of working in hot environments in Japan. However, acute heat strokes recently sometimes occurred in outdoor work environments such as industrial constructions and agriculture. Seasonal variations in weather are significant and the climatic conditions vary. The criteria are mainly set for working in mines, factories, and so on. WBGT is a useful evaluation index for hot environments; however, it is not commonly used for work practices. WBGT could be calculated and should be commonly used as a standard during summer. Japan mainly has a very hot and humid climate during summer. With regard to the thermal standard for offices, humidity also creates a problem in the indoor thermal conditions. Therefore, it is better to decide the TLVs of the thermal conditions according to seasons and activity levels. Inadequate thermal stress may cause discomfort and adversely affect the performance, safety, and harm to health. Further, thermal factors in the work environment must be measured and evaluated under light workload conditions like deskwork for safety and work efficiency.
\end{abstract}

Key words: Heat stress, Thermal standard, Work efficiency, Indoor thermal condition

\section{Occurrences of Heat Strokes during Work in Japan}

Earlier, acute heat strokes often occurred as a result of working in hot environments in Japan. The number of heat stroke occurrences, according to the statistics provided by the Ministry of Health, Labor and Welfare, categorized as on-the-job diseases was annually reported to be above 100 in 1955; most of these occurrences were diagnosed in the mining industry. In 1965, this number decreased rapidly with closing mines and coal mines and improvements in the workplace environment, such as air conditioning. However, after these events, acute heat strokes sometimes occurred in outdoor work environments such as industrial constructions and agriculture ${ }^{1)}$.

The occurrences of heat strokes during outdoor work were related to the weather conditions such as heat waves and geographical features such as inland areas or basins; the influences of these features on the climate were significant.
During intensely hot or cool summers, agriculture production or electricity consumption had a considerable social influence throughout Japan.

Based on newspaper reports regarding the heat stroke situation in Japan, the percentage of occurrences of heat strokes during work was $28.9 \%$; daily life activities, $38.4 \%$; and exercising, $32.7 \%$. Occurrences of heat strokes during outdoor work such as agriculture were observed mostly in persons older than 65 years and during daily life activities ${ }^{2,3)}$.

According to the database of the Fire Defense Agencies in the Fukushima prefecture regarding the emergency transportation records from 1991 to 1995 , a total of 435 cases of heat strokes and dehydrations were recorded; 193 of these cases (44.4\%) were recorded in August and 155 of these cases $(35.6 \%)$ in July. $18.6 \%$ of these heat disorders occurred during labor activities (outdoor work, agriculture, etc.), $26.9 \%$ during daily life activities, $33.5 \%$ during sports activities, and so on. A number of heat disorders in the elderly-in the seventies [67 cases (15\%)] and eighties [78 
cases (18\%)]—were diagnosed in rural areas; however, the number of cases diagnosed for children under 10 years of age and people in their fifties were fewer in the rural areas: 20 cases $(4.6 \%)$ and 34 cases $(7.8 \%)$ were reported, respectively (Fig. 1). The discomfort index is calculated from the air temperature and wet-bulb temperature. A large number of heat disorder cases at discomfort indexes of 80 84 and above 85 ranges were recorded: 169 (39\%) and 134 (3 $1 \%$ ), respectively.

A number of midsummer days-days with a maximum daily temperature of above $30^{\circ} \mathrm{C}$ - occurred from May to September; they occurred frequently in July and August ${ }^{4)}$. A significant positive correlation was found between the number of midsummer days and the cases of heat disorders in each month.

The typical workplaces that involve hot environments are blast furnaces, cupolas, and indoor workshops used for melting glass. Usually, a workshop environment is considered significantly hot when it has a dry-bulb air temperature exceeding $40^{\circ} \mathrm{C}$, wet-bulb air temperature exceeding $32.5^{\circ} \mathrm{C}$, glove temperature exceeding $50^{\circ} \mathrm{C}$, or effective temperature exceeding $32.5^{\circ} \mathrm{C}^{5}$.

Based on the data that related the thermal conditions with deaths due to heat strokes, an air temperature of around $40^{\circ} \mathrm{C}$ is considered to be safe for dry conditions such as those with humidity less than $10 \%$. However, the conditions become severe for work even for an air temperature of around $27^{\circ} \mathrm{C}$ in humid conditions with a relative humidity of near $100 \%{ }^{6}$. Therefore, a correlation is evident between the occurrence of heat strokes and humidity in hot work environments.

\section{Natural or Artificial Thermal Conditions}

Japan is an island country with the following main islands: Hokkaido is the northern island, Honshu is the main island, Shikoku is in the Inland Sea, and Kyushu is the southern island. From Hokkaido to Okinawa islands, Japan stretches from the latitudes $46^{\circ}$ to $24^{\circ}$. In Japan, seasonal variations in weather are significant and the climatic conditions vary.

Figure 2 shows the climograph of the selected cities in Japan and the world: Tokyo in Honshu, Sapporo in Hokkaido, Naha in Okinawa Island, London in U.K., Montreal in Canada, and San Jose in Costa Rica. In the figure, the number indicates the month. In Naha, the average annual air temperature was $22.7^{\circ} \mathrm{C}$ and the monthly average air temperatures ranged from $16.6^{\circ} \mathrm{C}$ in January to $28.5^{\circ} \mathrm{C}$ in July. The average annual humidity was $75 \%$ and the monthly average humidity ranged from $68 \%$ in December to $84 \%$ in

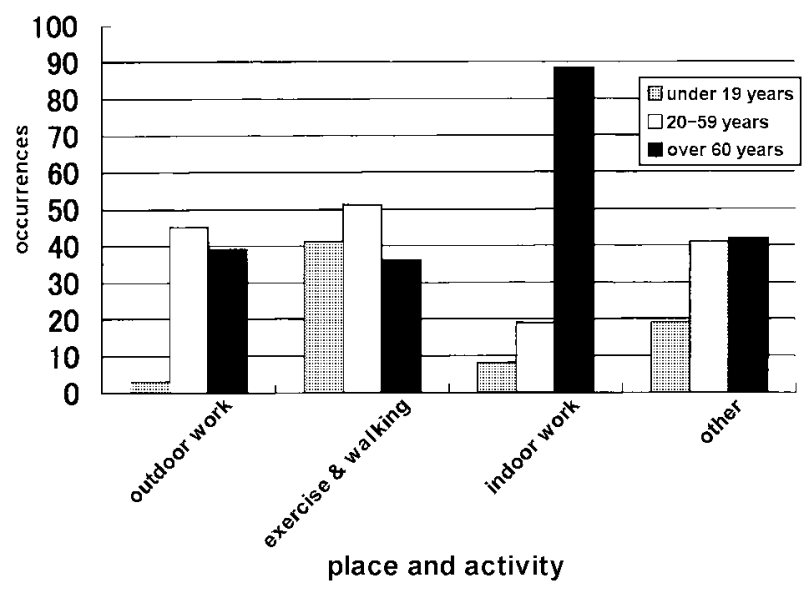

Fig. 1. Occurrences of heat strokes from 1991 to 1995 in Fukushima prefecture $^{4)}$.

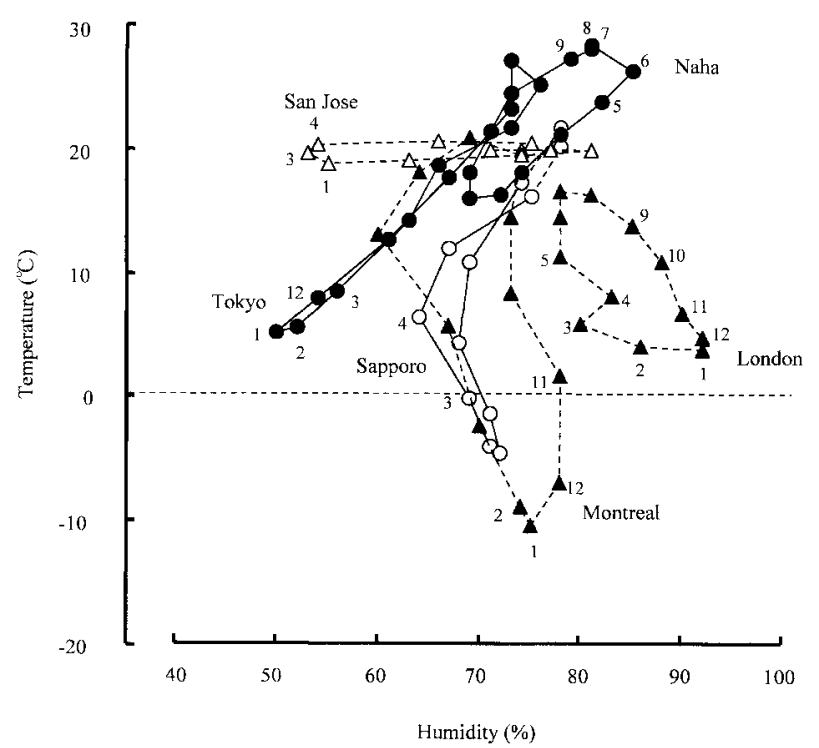

Fig. 2. Climograph of Tokyo, Sapporo, Naha, London, Montreal and San Jose.

June. In Sapporo, the average annual air temperature was $8.5^{\circ} \mathrm{C}$ and the monthly average air temperatures ranged from $-4.1^{\circ} \mathrm{C}$ in January to $22.0^{\circ} \mathrm{C}$ in August. The average annual humidity was $70 \%$ and the monthly average humidity ranged from $63 \%$ in April to $77 \%$ in July and August. In Tokyo, the average annual air temperature was $15.9^{\circ} \mathrm{C}$ and the monthly average air temperatures ranged from $-4.1^{\circ} \mathrm{C}$ in January to $27.1^{\circ} \mathrm{C}$ in August. The average annual humidity was $63 \%$ and the monthly average humidity ranged from $50 \%$ in January to $75 \%$ in July. Generally, the climate of Japan is hot and humid during summer and cool and dry during winter. Further, the climate of London is generally 
humid and has a neutral temperature. The climate of San Jose is constantly warm throughout the year and has dry and wet seasons. The climate of Montreal is cold and moderately humid during winter ${ }^{7,8}$.

Hot climatic conditions in summer directly influence the occurrence of diseases such as heat strokes and dehydration. Further, seasonal climatic conditions are indirectly related to the risk factors of diseases such as Japanese encephalitis and malaria. People living in rural areas are accustomed with the natural conditions, and they are sometimes exposed to severe weather conditions. On the other hand, most people in urban areas are accustomed with artificial conditions; they have access to air-conditioning systems during hot seasons, resulting in frequent occurrences of cooling disorders.

Using the vital statistics of the seasonality of monthly deaths in Japan, the death rate due to infectious diseases showed two peaks earlier-one in summer and one in winter. Also, a second peak was observed in summer (August and July). In 1950, a similar tendency to that in 1947 was observed. In summer, gastrointestinal diseases, infectious diseases, Japanese encephalitis, and so on were commonly diagnosed. According to the seasonal disease calendar from 1906 to 1910 , the death rates due to digestive diseases such as dysentery, diarrhea, and inflammation of the intestine and other diseases such as beriberi, tuberculosis, and whooping cough were higher in summer. After $50 \mathrm{yr}$, from 1957 to 1961, the death rate only from dysentery was high in summer. In recent year, deaths from many diseases were common in winter, with the exception of malignant neoplasm, infectious diseases and suicide. The death rate from suicide was higher from March to July and lower in winter. There were many suicides in the generation over $45 \mathrm{yr}$ old, especially males ${ }^{9,10)}$.

Overexposure to a certain range of ultraviolet rays is one of the undisputed causes of skin cancer. In this case, people have an increased chance of being exposed to cancer-inducing ultraviolet irradiation during summer. Ultraviolet radiation is beneficial to life in moderation, but harmful in excess ${ }^{11)}$.

Mortalities from seasonal diseases or meteorological factors are associated with the environmental conditions. Physical conditions such as light, temperature, pressure in natural or artificial climates, and mental and social conditions such as culture and economy can be associated in the form of a single factor or a complex set of factors.

\section{Thermal Standards for Work Environment}

In Japan, the heat and cold stress threshold limit values (TLVs) are decided by the Society for Occupational Health and the thermal standard for offices is decided by the Ministry of Health, Labor and Welfare.

TLVs are intended to protect workers from the severest effects of thermal stress and to establish the exposures to heat in working conditions under which nearly all the workers can be repeatedly exposed to without any adverse health effects.

Table 1 shows the criteria for the occupational exposure limits for heat stress in Japan ${ }^{12)}$. These criteria are described for healthy male workers, who were acclimatized and wore normal working clothes for summer as well as drank adequate salt water with a salt concentration of around $0.1 \%$. The working period was either continuous for one hour or intermittent for two hours. These criteria are mainly set for working in mines, factories, and so on. The assessment of heat stress can be used for evaluating the risk to workers with regard to safety and health. As the heat stress approaches the human tolerance limits, the risk of heat-related disorders increases.

At high environmental temperatures, the addition of a vapor-impermeable clothing barrier may significantly increase the heat stress for the individual wearer and heat exhaustion may rapidly occur.

The wet bulb glove temperature index (WBGT) provides a useful, first-order index of the environmental contribution to heat stress; it is influenced by air temperature, radiant heat, and humidity ${ }^{13}, 14$.

WBGT values are calculated using one of the following equations:

- Direct exposure to sunlight:

$$
\text { WBGT out }=0.7 \mathrm{Tnwb}+0.2 \mathrm{Tg}+0.1 \mathrm{Tdb}
$$

- Without direct exposure to sunlight:

$$
\text { WBGT in }=0.7 \mathrm{Tnwb}+0.3 \mathrm{Tg}
$$

In the above equations, Tnwb denotes the natural wetbulb temperature; $\mathrm{Tg}$, the glove Temperature; and Tdb, the dry-bulb air temperature.

Generally, the relative metabolic rate (RMR) is used as the workload unit for occupational health in Japan ${ }^{12}$. RMR is calculated as follows:

$$
\mathrm{RMR}=\frac{\text { Energy at work }- \text { Energy at rest }}{\text { Basal metabolic energy }}
$$

Where, the basal metabolic energy is calculated using the body surface area $\left(\mathrm{m}^{2}\right)$, which is calculated using the body weight $(\mathrm{kg})$ and body height $(\mathrm{cm})$. The "very light" workload categories are those categorized as RMR 1 and below. Examples of activities in this category are car driving and 
Table 1. Occupational exposure limits (OELs) for heat stress in Japan $^{12)}$

\begin{tabular}{lcc}
\hline \multicolumn{1}{c}{ Work Load } & \multicolumn{2}{c}{ OELs } \\
\cline { 2 - 3 } & WBGT $\left({ }^{\circ} \mathrm{C}\right)$ & $\mathrm{CET}^{* *}\left({ }^{\circ} \mathrm{C}\right)$ \\
\hline RMR $*$-1 (Very light, $-130 \mathrm{kcal} / \mathrm{h})$ & 32.5 & 31.6 \\
RMR -2 (Light, $-190 \mathrm{kcal} / \mathrm{h})$ & 30.5 & 30.0 \\
RMR -3 (Moderate, $-250 \mathrm{kcal} / \mathrm{h})$ & 29.0 & 28.8 \\
RMR -4 (Moderate, $-310 \mathrm{kcal} / \mathrm{h})$ & 27.5 & 27.6 \\
RMR -5 (Heavy, $-370 \mathrm{kcal} / \mathrm{h})$ & 26.5 & 27.0 \\
\hline
\end{tabular}

*: Relative Metabolic Rate $($ RMR $)=($ Metabolic energy expenditure during work-Metabolic energy expenditure at rest)/Basel metabolic rate corresponding to the work period.

**: Corrected effective temperature.

deskwork such as writing. The "light" workload categories are those categorized as RMR 1-2. Examples of activities in this category are those that involve standing work during like a watching operation or walking at about $45 \mathrm{~m} / \mathrm{min}$. The "moderate" workload categories are those categorized as RMR 2-3. Examples of activities in this category are walking at $70-95 \mathrm{~m} / \mathrm{min}$ or cleaning a floor. The "slight heavy" workload categories are those categorized as RMR 3-4. Examples of activities in this category involve cycling at about $170 \mathrm{~m} / \mathrm{min}$ or using a grinder. The "heavy" workload categories are those categorized as RMR 4-5. Examples of activities in this category are sawing by hand or riveting.

In Japan, the workload is mostly categorized as RMR 12 with regard to automation or mechanization. A worker with a workload of RMR 4 can work continuously for one hour, whereas that with a workload of above RMR 4 may work intermittently. For example, the TLVs indicate that a "light" workload categorized as RMR 1-2 requires an environment with a WBGT of $30.5^{\circ} \mathrm{C}$ (Table 1).

Table 2 shows the criteria with regard to environmental conditions for office buildings in Japan. The thermal standard for offices is intended for office workers to work safely and comfortably. The air temperature in office buildings is 17 $28^{\circ} \mathrm{C}$. The relative humidity is $40-70 \%$ and the air velocity is below $0.5 \mathrm{~m} / \mathrm{s}^{15,16)}$.

Japan mainly has a very hot and humid climate during summer. With regard to the thermal standard for offices, humidity also creates a problem in the indoor thermal conditions. Therefore, it is better to decide the TLVs of the thermal conditions according to seasons and activity levels.

WBGT is a useful evaluation index for hot environments; however, it is not commonly used for work practices in Japan. The air and wet-bulb temperatures were commonly used in Japan; therefore, the effective temperature was introduced along with these factors. Further, the glove temperature was useful in radiant heat environments; therefore, the corrected effective temperature (CET) was introduced along with the glove and wet-bulb temperatures ${ }^{12)}$. CET is calculated from the following equation:

$$
\mathrm{CET}=0.786 \mathrm{WBGT}+6.0\left({ }^{\circ} \mathrm{C}\right)
$$

The meteorological observatories and weather stations in Japan record the air temperature, wet-bulb temperature, and wind velocity as the thermal factors. It is preferable to measure the glove temperature. Therefore, the WBGT value could be calculated and should be commonly used as a standard during summer in Japan.

Weather information is useful in summer in order to prevent heat disorders. In this case, the weather is variable; it can be temporarily sunny, cloudy, or rainy. Therefore, only one equation may be sufficient for the calculation of WBGT values, that is, $\mathrm{WBGT}=0.7 \mathrm{Tnwb}+0.2 \mathrm{Tg}+0.1 \mathrm{Tdb}$. Without any direct exposure to sunlight, the glove temperature almost becomes the same as the dry-bulb air temperature. Further, the wind velocity should be included for the evaluation of the environment.

\section{Safety, Work Efficiency, and Thermal Environment}

Thermal stress during work is the net thermal load that a worker may be exposed to the combined contribution of metabolic cost of work, environmental factors (air temperature, humidity, air velocity, and radiant heat exchange), and clothing requirements. Inadequate thermal stress may cause discomfort and adversely affect the performance, safety, and harm to health. Occupational exposure to hot and cold environments may have an adverse effect on the performance, health, and comfort of the workers. Such thermal conditions are observed in several outdoor jobs and indoor works. Hot working conditions are regarded as one of the main causes of accidents, illnesses, and other health problems.

Hard work or training under hot conditions has led to a marked increase in heat casualties and heat disorders, such as heat exhaustion, heat stroke, and heat syncope, often in combination with dehydration. The most serious consequence of exposure to intense heat is heat stroke, which may be fatal. It is caused by a sudden collapse in temperature regulation, leading to a marked increase in the heat content of the body. The rectal temperature may be $40^{\circ} \mathrm{C}$ or higher ${ }^{17,18)}$.

The relationships between the heart rate and core body temperature were discussed, and the regression lines for body 
Table 2. Threshold limit values of environmental condition at office building in Japan ${ }^{16)}$

\begin{tabular}{|c|c|c|c|c|}
\hline Item & Standard at present & \multicolumn{3}{|c|}{ Comfort standard (propose) } \\
\hline Air temperature & $17-28^{\circ} \mathrm{C}$ & $\begin{array}{l}\text { summer } \\
\text { winter }\end{array}$ & $\begin{array}{l}\text { sitting work } \\
24-27^{\circ} \mathrm{C} \\
20-23^{\circ} \mathrm{C}\end{array}$ & $\begin{array}{c}\text { standing work } \\
20-25^{\circ} \mathrm{C} \\
18-20^{\circ} \mathrm{C}\end{array}$ \\
\hline Air velocity & $<0.5 \mathrm{~m} / \mathrm{s}$ & & $<0.5 \mathrm{~m} / \mathrm{s}$ & \\
\hline Humidity & $40-70 \%$ & & $50-60 \%$ & \\
\hline $\mathrm{CO}_{2}$ & $\begin{array}{l}\text { office with central air conditioning system }<0.1 \% \\
\text { office without central air conditioning system }<0.5 \%\end{array}$ & & $<0.1 \%$ & \\
\hline $\mathrm{CO}$ & $10 \mathrm{ppm}, 50 \mathrm{ppm}$ & & $<10 \mathrm{ppm}$ & \\
\hline Ambient dust & $<0.15 \mathrm{mg} / \mathrm{m}^{3}$ & & $<0.15 \mathrm{mg} / \mathrm{m}^{3}$ & \\
\hline Air volume & $10 \mathrm{~m}^{3} /$ person & & $10-13 \mathrm{~m}^{3} /$ person & \\
\hline Ventilation air volume & - & & $30 \mathrm{~m}^{3} /$ person $/ \mathrm{h}$ & \\
\hline
\end{tabular}

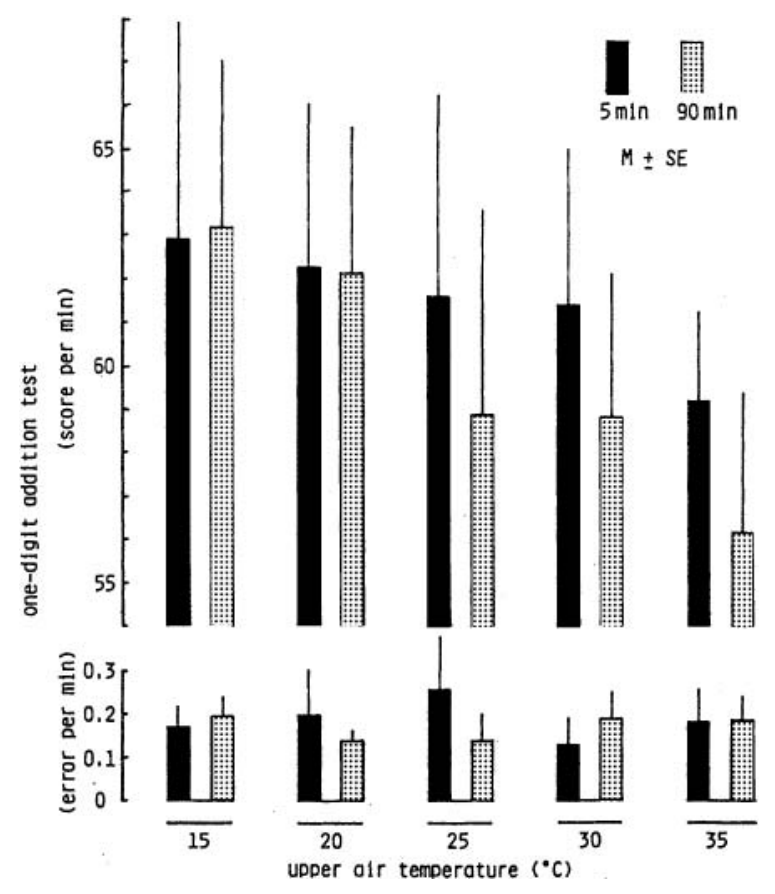

Fig. 3. The mean values of scores and errors of the one-digitaddition test at $5 \mathrm{~min}$ and $90 \mathrm{~min}$ according to different vertical air temperatures $(\mathrm{N}=6)^{20)}$.

temperature on the heart rate were formulated for work safety ${ }^{19,20)}$.

At high environmental temperatures, the addition of a vapor-impermeable clothing barrier significantly increases the heat stress for the individual wears and heat exhaustion occurs rapidly ${ }^{20)}$.

Heart disorders, resulting due to thermal stress would occur during transit, where the workers move from the hot workplace to a cool place for relaxation. Workers suffering from heart diseases, abnormalities in the ECG, hypertension, and so on require to consider the thermal conditions, particularly elderly people who would have heart disorders or blood circulation problems. Workers must undergo regularly health checkups.

During deskwork, with regard to the relationship of peak performance at a certain level of arousal, deterioration in performance either at low or high arousal levels occurred; the arousal levels reduced comfort and the hot temperatures affected the performance. The paradox of improving instead of deteriorating the mental performance under certain thermal stress levels is explained by the inverted U-shaped relationship between arousal and performance. Comfortable conditions reduced the arousal level. Slightly uncomfortable air temperature or humidity elevated arousal, which improved the performance. This has been observed in many task performances such as arithmetic visual judgments, auditory performance, skill, and reaction time. Increasing or decreasing the ambient temperature eventually increased the arousal level beyond its optimum value to a range where the performance deteriorated. The strain of increasing or decreasing the body temperature, which became overarousing after a period of time, resulted in a reduction in the performance ${ }^{199}$.

The upper body of the subject was exposed to air temperatures of $15^{\circ} \mathrm{C}, 20^{\circ} \mathrm{C}, 25^{\circ} \mathrm{C}, 30^{\circ} \mathrm{C}$, or $35^{\circ} \mathrm{C}$, whereas the lower part was subjected to a constant air temperature of $30^{\circ} \mathrm{C}$. Slight differences were observed between the values at $5 \mathrm{~min}$ and $90 \mathrm{~min}$ in the scores of the one-digit-addition test for the upper-body air temperatures of $15^{\circ} \mathrm{C}$ and $20^{\circ} \mathrm{C}$. However, the values at $90 \mathrm{~min}$ were lower than those at 5 min at the upper-body air temperatures of $25^{\circ} \mathrm{C}, 30^{\circ} \mathrm{C}$, and $35^{\circ} \mathrm{C}$. The scores decreased with an increase in the upperbody air temperature, particularly at $90 \mathrm{~min}$. The number of errors was slightly greater at $5 \mathrm{~min}$ at an upper-body air temperature of $25^{\circ} \mathrm{C}$ (Fig. 3). The values of discomfort 
sensation at $5 \mathrm{~min}$ and $90 \mathrm{~min}$ at the upper-body air temperatures of $20^{\circ} \mathrm{C}, 25^{\circ} \mathrm{C}$, and $30^{\circ} \mathrm{C}$ were similar; however, the values at $90 \mathrm{~min}$ at the upper-body air temperatures of $15^{\circ} \mathrm{C}$ and $35^{\circ} \mathrm{C}$ were greater than that at $5 \mathrm{~min}$; in other words, there was an increase in the amount of discomfort. Mildly uncomfortable ambient conditions, where the upperbody air temperatures were cool and lower-body air temperatures were warm, improved the performance; however, at an upper-body air temperature of $35^{\circ} \mathrm{C}$, the performance deteriorated as the subjects felt uncomfortable and hot $^{211}$.

With regard to work practices in severe conditions, the workers should be under protective observation such as a buddy system or supervision, and the workers should be instructed with regard to safety and health procedures. Further, thermal factors in the work environment must be measured and evaluated under light workload conditions like deskwork for safety and work efficiency.

\section{References}

1) Miura $T$ (1977) Hot, cold and human being — approach to thermal comfort, Cyuou Kouronsha Co. Ltd., Tokyo (in Japanese).

2) Nakai $S$, Itoh $T$, Morimoto $T$ (1999) Deaths from heat-stroke in Japan 1968-1994. Int J Biometeorology 43, 124-7.

3) Nakai S, Shinzato K, Morimoto T (1996) Epidemiological analysis of heat disorders in Japan. Jpn J Biometeorol 33, 71-7 (in Japanese).

4) Tanaka M, Watanabe T, Satoh M, Tanaka K (1997) Occurrences of heat disorder in Fukushima prefecture. Japan J Biometeorology 34, 29 (in Japanese).

5) Japan Industrial Safety \& Health Association (Ed.) (1983) Law and regulations index, Japan Industrial Safety \& Health Association, Tokyo.

6) Committee of Human-Environmental System (Ed.) (1972) Human-environmental system Vol. 1, Human and Technique Co., Ltd., Tokyo (in Japanese).
7) National Astronomical Observatory (Ed.) (1994) Chronological scientific table 1995, Maruzen Co., Ltd., Tokyo (in Japanese).

8) National Astronomical Observatory (Ed.) (2005) Chronological Scientific Table 2006, Maruzen Co., Ltd., Tokyo (in Japanese).

9) Momiyama M, Katayama K (1976) Biometeorology of disease and death. In: Handbook of internal medicine, Yoshitoshi Y, et al. (Eds.) Nakayama Co., Ltd., Tokyo (in Japanese).

10) Tanaka M (1998) Tendency of seasonal disease in Japan. Global Environmental Research 12, 169-76.

11) Thomson WAR (1979) A change of air, Adam and Charles Black Co., Ltd., London.

12) Japan Society for Occupational Health (2005) Recommendation of occupational exposure limits 2005-2006. J Occup Health 47, 354-70.

13) American Conference of Governmental Industrial Hygienists (2002) Threshold limits values and Biological exposure indices 2001.

14) ISO 7933 (1989) Hot environments-Analytical determination and interpretation of thermal stress using calculation of required sweat rate.

15) Maintenance of building sanitation —-2005— (2005) Dai-Ichi Houki Co., Ltd., Tokyo (in Japanese).

16) Tanaka M (2002) Tendency of health medicine - on the view point of environmental hygiene. Fukushima Med J 52, 275 83 (in Japanese).

17) Fanger PO (1970) Thermal comfort, McGraw-Hill Co., Ltd., New York.

18) Rosen S (1979) Weathering, M.Evans and Co., Inc., New York.

19) Kamon E (1975) Ergonomics of heat and cold. Tex Rep Biol Med 33, 145-82.

20) Tanaka M, Burisson GB, Voll MA (1978) Body temperature in relation to heart rate for workers wearing impermeable clothing in a hot environment. Am Ind Hyg Assoc J 39, 885-90.

21) Tanaka M, Ohnaka T, Yamazaki S, Tochihara Y (1987) The effects of different vertical air temperatures on mental performance. Am Ind Hyg Assoc J 48, 494-8. 